\title{
Quercetin Reduces Hepatic Fibrogenesis by Inhibiting TGF- $\beta /$ Smad3 Signaling Pathway in LX-2 Cell Line
}

\author{
Elham Shakerian (iD) ${ }^{1}$, Rasoul Akbari (iD ${ }^{1}$, Narges Mohammadtaghvaei (iD) ${ }^{2}$, Mehrnoosh Mohammadi \\ Gahrooie (iD ${ }^{1}$ and Reza Afarin (iD ${ }^{3, *}$ \\ ${ }^{1}$ Student Research Committee, Ahvaz Jundishapur University of Medical Sciences, Ahvaz, Iran \\ ${ }^{2}$ Hyperlipidemia Research Center, Department of Laboratory Sciences, School of Paramedical Sciences, Ahvaz Jundishapur University of Medical Sciences, Ahvaz, Iran \\ ${ }^{3}$ Hyperlipidemia Research Center, Department of Clinical Biochemistry, School of Medicine, Ahvaz Jundishapur University of Medical Sciences, Ahvaz, Iran \\ "Corresponding author: Student Research Committee, Ahvaz Jundishapur University of Medical Sciences, Ahvaz, Iran. Email: r.afarin1988@gmail.com
}

Received 2021 February 04; Revised 2021 June 18; Accepted 2021 June 25.

\begin{abstract}
Background: Liver fibrosis has become one of the leading causes of morbidity and mortality in the world. Liver fibrosis progresses to cirrhosis and can eventually lead to hepatocellular carcinoma (HCC). During fibrogenesis, the hepatic stellate cells (HSCs) remain active and continuously produce more extracellular matrix (ECM). Quercetin, one of the main flavonoids in vegetables, has shown hepatoprotective potential, but its effects on liver fibrosis are not apparent.

Objectives: In this study, we investigated the antifibrotic activity of quercetin following stimulation of TGF- $\beta$ in the LX-2 cell line (a type of HSC-derived cell line) and its underlying mechanism in vitro.

Methods: The LX-2 cells were treated with TGF- $\beta 1(2 \mathrm{ng} / \mathrm{mL})$ for $24 \mathrm{~h}$. Next, the cells were treated with quercetin for $24 \mathrm{~h}$, and the mRNA expression of $\alpha$-smooth muscle actin ( $\alpha$-SMA), collagen1 $\alpha 1$, and p-Smad3 protein levels were measured.

Results: The results showed that the expression of $\alpha$-SMA, collagen $1 \alpha 1$ (COL1 $\alpha 1$ ) genes, and also the level of p-Smad 3 protein in the presence of TGF- $\beta$ increased significantly compared to the control group. Moreover, quercetin in concentrations of 75 and $100 \mu \mathrm{M}$ inhibited TGF- $\beta$-induced expression of $\alpha$-SMA and COL1 $\alpha 1$ genes and the p-Smad3 protein in LX-2 cells.

Conclusions: We conclude that quercetin inhibits further activation of HSCs by inhibiting the TGF- $\beta /$ Smad 3 signaling pathway and reduces ECM accumulation during liver fibrosis in vitro, and may prevent the progression of liver fibrosis. Thus, the use of quercetin is suggested as a potential therapeutic agent in the treatment of liver fibrosis.

Keywords: HSCs/LX-2, Quercetin, TGF- $\beta /$ Smad3C, Cell Line
\end{abstract}

\section{Background}

Liver fibrosis has become one of the important causes of morbidity and mortality in the world. Following liver damage, hepatic stellate cells (HSCs) are activated, which are important sources of extracellular matrix (ECM) production. Liver fibrosis progresses to cirrhosis and can eventually lead to hepatocellular carcinoma (HCC) $(1,2)$. Several factors can activate HSCs and contribute to the progression of liver fibrosis, including alcohol consumption, drug abuse, hepatitis virus infection, and growth factors (3).

Among the growth factors, transforming growth factor (TGF- $\beta$ ) plays an important role during the HSCs activation. Dysregulation of TGF- $\beta$ signaling pathways contributes to the progression of liver fibrosis (4). TGF- $\beta$ participates in the liver fibrosis processes by enhancing the synthesis of collagen type 1 and other ECM proteins (5). Smad proteins are intracellular mediators of the TGF- $\beta$ sig- naling pathway that demonstrate important roles in this pathway $(6,7)$. During fibrogenesis, the HSCs remain active and continuously produce more ECM. The accumulation of excessive matrix is associated with an insufficiency of liver function and predisposition to the expansion of HCC (8). For this reason, new therapeutic approaches are considered to prevent the progression of liver fibrosis by returning HSCs from an active to inactive state (9).

Nowadays, there are new methods for reducing the severity of liver fibrosis, such as targeting kinase receptors and degradation of the ECM proteins. Therefore, the study of the effect of drugs for the treatment of liver fibrosis and accurate knowledge of signaling pathways in the progression of liver fibrosis can help find the best ways to reduce and treat this disease. Finding and implementing appropriate therapies remain a severe challenge for science (9, 10).

Quercetin (3, 3', 4', 5, 7-pentahydroxyflavone) belongs 
to the flavonols class that cannot produce in the human body. Quercetin is the most common bioflavonoid in vegetables. It is known for its antioxidant properties, anti-inflammatory effects, anti-hypertensive, vasodilating effects, anti-hypercholesterolemic (11), anti-carcinogenic, anti-viral, inhibition of lipid peroxidation, and platelet aggregation (12). Quercetin can reduce inflammatory cytokines, such as IL-1 $\beta$, and alleviate metabolic and inflammatory disorders (13).

Treatment with quercetin dramatically suppressed NF$\kappa \mathrm{B}$ activation in mice. Moreover, quercetin attenuated reactive oxygen species production, mitochondrial dysfunction, and cell death (14). However, the ability of quercetin to prevent the progression of liver fibrosis as an inhibitor of some signaling pathways involved in fibrosis, has not been fully investigated.

\section{Objectives}

The purpose of the present study was to investigate the effect of quercetin on liver fibrosis in HSC lines (LX-2 cell line) by examining the effects of quercetin on the TGF- $\beta$ signaling pathway and collagen expression. Our results demonstrate that quercetin inhibits TGF- $\beta /$ Smad3 signaling and inhibiting the activation of HSCs; thus, quercetin may act as an influential factor in preventing liver fibrosis.

\section{Methods}

\subsection{Chemicals and Reagents}

Quercetin, MTT (3-4, 5-Dimethylthiazol-2-yl)-2, 5diphenyltetrazolium bromide), RIPA buffer and TGF- $\beta$ were purchase from Sigma-Aldrich (St. Louis, MO, United States). The antibodies used in this study included antiGAPDH, anti-Smad3, and secondary anti-rabbit that were purchased from Abcam (United Kingdom). The Dulbecco's modified Eagle's medium (DMEM) medium, FBS (fetal bovine serum), Trypsin-EDTA, and antibiotic (PenicillinStreptomycin) were obtained from (Idezist, Iran). The Chemiluminescent detection kit (Bio-Rad Laboratories, Inc. USA) and bicinchoninic acid (BCA) kit (Parstous, Iran) were used. Dimethyl sulfoxide (DMSO) was purchased from (Sinaclon, Iran). The present study was designed and conducted with the permission of the Ethics Code (IR.AJUMS.REC.1399.650).

\subsection{Cell Culture Conditions}

The LX-2 cells, gifted by Professor Scott Friedman, were cultured in DMEM Low Glucose, containing 10\% FBS in a $5 \% \mathrm{CO}_{2}$ atmosphere at $37^{\circ} \mathrm{C}$. After starvation, the cells were treated with TGF- $\beta 1(2 \mathrm{ng} / \mathrm{mL})$ for $24 \mathrm{~h}$ (15). To prepare quercetin solution, a certain amount of quercetin was dissolved in DMSO according to the manufacturer's instructions and stored at $-20^{\circ} \mathrm{C}$. Then different concentrations were added to the cell culture medium.

\subsection{MTT Assay}

Cell viability was evaluated using the MTT assay. The LX2 cells were dispensed into 96 well plates in 5,000 cells/well and incubated for $24 \mathrm{~h}$ at $37^{\circ} \mathrm{C}$ to allow attachment. When the LX-2 cells reached 80 - 90\% confluency, the medium was treated with a complete medium consisting of different concentrations of quercetin $(25,50,75,100,125$, and $150 \mu \mathrm{M}$ ) for $24 \mathrm{~h}(16)$. After removing the supernatant, the cells were incubated with MTT ( $5 \mathrm{mg} / \mathrm{mL}$ in PBS) for $4 \mathrm{~h}$. After that, DMSO was added to dissolve the formazan crystals formed, and the absorbance was read at $570 \mathrm{~nm}$ by an ELISA plate reader. The results were expressed as a percent of the untreated control. Each different concentration was repeated in triplicate.

\subsection{Quantitative RT-PCR}

Total RNA was extracted using the QIAGEN RNA isolation kit (Germany) according to the manufacturer's protocol. After RNA extraction, analysis of purified RNA quality was probing by gel electrophoresis, and expected RNA bands were seen. Complementary DNA(cDNA) was synthesized using the cDNA synthesis Kit (Yekta Tajhiz, Iran).

Primers used for real-time PCR technique: (1) collagen-1 (forward: 5'-CCTGGATGCCATCAAAGTCT-3', reverse: $\quad 5^{\prime}$-CGC-CATACTCGAACTGGAAT- $3^{\prime}$ ); (2) $\alpha$ SMA (forward: $\quad 5^{\prime}$-CCGGGAGAAAATGACTCAAA-3' , reverse: 5'-GCAAGGCATAGCCCTCATAG-3'); and (3) GAPDH (forward: 5'-TTCACCACCATGGAGAAGGC-3', reverse: $5^{\prime}$ GGCATGGACTGTGGTCATGA-3'), which was used as the housekeeping gene for normalization.

\subsection{Western Blotting}

Cells were lysed in RIPA lysis buffer for $20 \mathrm{~min}$ at $4^{\circ} \mathrm{C}$. After that, total protein concentration was measured using a BCA protein detection kit (Parstous, Iran). Equal amounts of extracted protein samples were loaded onto a $10 \%$ SDS-PAGE gel and transferred onto polyvinylidene fluoride (PVDF) membranes (Millipore, USA). After blocking with $5 \%$ bovine serum albumin at room temperature for $1 \mathrm{~h}$, the membrane was incubated in anti-Smad3 or antiGAPDH antibody with a gentle shaking overnight at $4^{\circ} \mathrm{C}$. Then, the membrane were incubated with the appropriate horseradish peroxidase-conjugated secondary antibody at room temperature. Subsequently, PVDF membrane was incubated with an ECL system for detecting signals on a ChemiDoc device. Image J software was used to calculate the expression of each protein. 


\subsection{Statistical Analysis}

All experiments were performed with three replications. The data were analyzed as (means \pm SEM) using ANOVA and Tukey post hoc test with Prism 9 software. The significance level was considered $\mathrm{P}<0.05$.

\section{Results}

\subsection{The Effect of Quercetin on the Survival of HSCS}

Different concentrations of quercetin $(25,50,75,100$, 125 , and $150 \mu \mathrm{M}$ ) were examined by MTT assay at $24 \mathrm{~h}$. At a concentration of $125 \mu \mathrm{M}$ quercetin, the percentage of cell survival was significantly reduced $(\mathrm{P}<0.001$, Figure $1 \mathrm{~A}$ and $B)$. Therefore, concentrations lower than IC50 were used to study gene expression.

\subsection{Inhibitory Effect of Quercetin on HSCS Activation}

To evaluate the expression of $\alpha$-smooth muscle actin ( $\alpha$-SMA) and collagen $1 \alpha 1$ (COL1 $\alpha 1$ ), the cells were incubated with a concentration of $2 \mathrm{ng} / \mathrm{mL}$ TGF- $\beta$ for 24 hours. The expression levels of $\alpha$-SMA and COL1 $\alpha 1$ were increased compared to the control group $(\mathrm{P}<0.01)$. Then the cells were treated for $24 \mathrm{~h}$ with concentrations of $25,50,75$, and $100 \mu \mathrm{M}$ of quercetin. The expression levels of $\alpha$-SMA and COL1 $\alpha 1$ in the presence of quercetin were significantly reduced compared to the TGF- $\beta$ group (Figure $2 \mathrm{~A}$ and B).

\subsection{Inhibitory Effect of Quercetin on Smad3 Activation}

To investigate the relationship between quercetin and the TGF- $\beta /$ Smad3C signaling pathway in HSCs, at first, the cells were treated with concentrations of $25,50,75$, and 100 $\mu \mathrm{M}$ of quercetin for $30 \mathrm{~min}$; then, the cells were treated with a concentration of $2 \mathrm{ng} / \mathrm{mL}$ TGF- $\beta$ for $30 \mathrm{~min}$. Compared to the control group, the level of phosphorylation of Smad3C (p-Smad3C) in the TGF- $\beta$ group increased significantly. Also, quercetin significantly inhibited the increase in the p-Smad3C levels compared to the TGF- $\beta$ group (Figure $3 \mathrm{~A}$ and $\mathrm{B})$.

\section{Discussion}

Liver fibrosis is one of the main causes of mortality in chronic liver disease due to hepatocyte damage and activation of HSCs (17). In the progression of liver fibrogenesis, activated HSCs play an important role as the main source of ECM production in the liver (18). Increasing evidence suggests that TGF- $\beta 1$ is a crucial mediator by activating its downstream Smad signaling pathway in the pathogenesis of liver fibrosis (19). Excessive TGF $\beta 1$ expression leads to HSC activation and collagen deposition in the liver, thereby giving significant evidence for the stimulatory role of TGF$\beta 1$ in liver fibrogenesis (20).

Currently, the lack of effective antifibrotic drugs in the prevention and treatment of liver fibrosis is a major global problem. Therefore, many studies are conducted to find effective and promising hepatic antifibrotic agents (17). Quercetin is a natural flavonoid that has strong antioxidant properties and activates superoxide dismutase and catalase. Quercetin exhibits many biological activities including, anti-inflammatory and liver protection. Previous studies have evaluated the effects of quercetin on liver fibrosis, but its impacts on signaling pathways are not apparent (21). This study aimed to investigate the antifibrotic effects of quercetin and its role in the TGF- $\beta 1$ signaling pathway in a model of induced hepatic fibrosis with TGF$\beta 1$.

We evaluated collagen synthesis and activated HSCs markers by measuring the mRNA expression levels of COL1 $\alpha 1$ and $\alpha$-SMA genes, respectively. We found that the expression levels of these fibrogenic markers were significantly lower than the control group compared to quercetin treatments (Figure 2A and B). As shown in our study, phosphorylation of Smad3 (p-Smad3) protein was significantly increased in the LX-2 by TGF- $\beta$, but it was reduced by quercetin (Figure $3 \mathrm{~A}$ and $\mathrm{B}$ ). The underlying molecular mechanisms for the effect of quercetin involved inhibition of HSCs activation and reduced expression of $\alpha$ SMA and COL1 $\alpha 1$, resulting from blocking TGF- $\beta 1 /$ Smad signaling. According to our study, the study of Wu et al. reported that quercetin could inhibit HSCs activity and possibly decrease autophagy by affecting the TGF- $\beta 1 /$ Smad signaling pathway. The productions of ECM, collagen I, and $\alpha$ SMA are inhibited (22). These data are in agreement with the results of studies that quercetin treatment inhibits HSC activation and the expression of collagen, TGF- $\beta 1$, and a-SMA markers in vivo (23).

The study of Yang et al. suggested that isorhamine (the 3'-O-methylated metabolite of quercetin) inhibits the TGF$\beta /$ Smad signaling pathway and relieves oxidative stress. Therefore, it prevents the activation of HSC and prevents liver fibrosis (24). Studies have also shown that the addition of methyl group to on functionally important position can increase the antifibrotic effect of quercetin in the treatment of liver fibrosis (25).

As expected, COL1 $\alpha 1, \alpha$-SMA mRNA, and p-Smad3 protein were upregulated in LX-2 cell line induced by $2 \mathrm{ng} / \mathrm{mL}$ TGF- $\beta$ for $24 \mathrm{~h}$, while all were suppressed by quercetin treatment. These data are consistent with the observations of Li et al., who showed that quercetin treatment inhibited HSC activity in vitro by affecting the expression of COL1 $\alpha 1$, TGF- $\beta 1$, and $\alpha$-SMA markers (26). In the present study, quercetin in concentrations of 75 and $100 \mu \mathrm{M}$ inhib- 
A

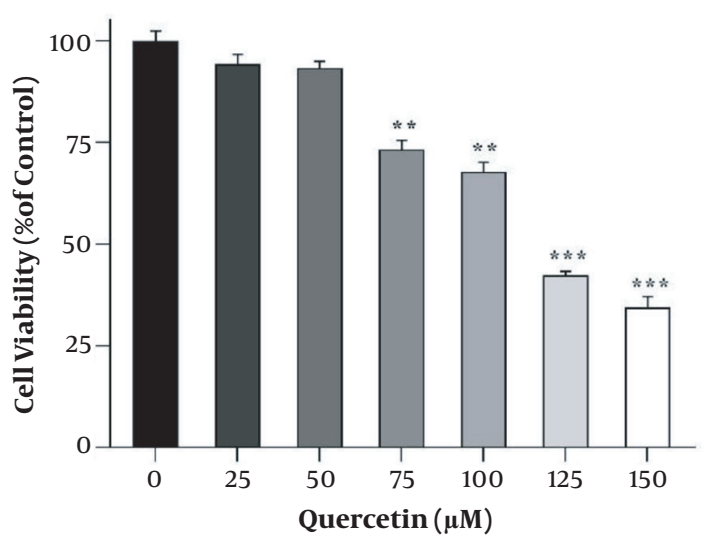

B

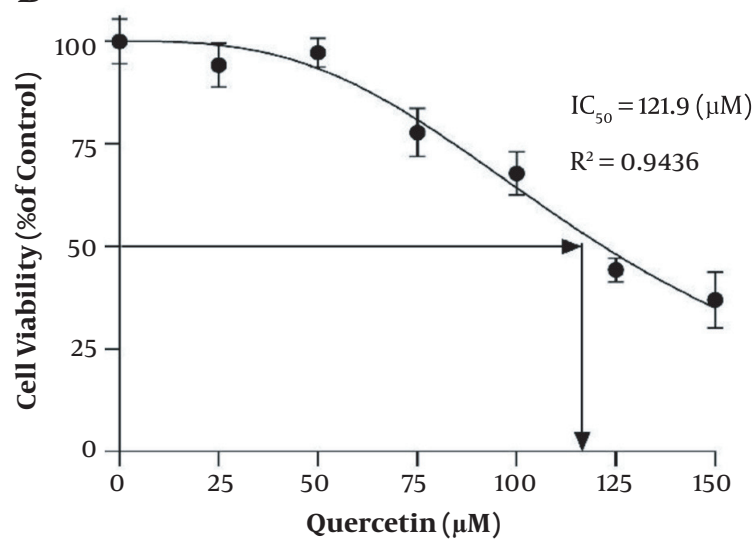

Figure 1. Effect of different concentrations of quercetin on the survival of LX2 cells. A, B, MTT assay results showing cell viability under different quercetin concentrations over 24 h. Results are shown as mean \pm SEM. Statistical analysis was performed by one-way ANOVA and Tukey post hoc test using GraphPad Prism 9 software ${ }^{* *} \mathrm{P}<0.01$, ${ }^{* * *} \mathrm{P}<$ $0.001)$.

A

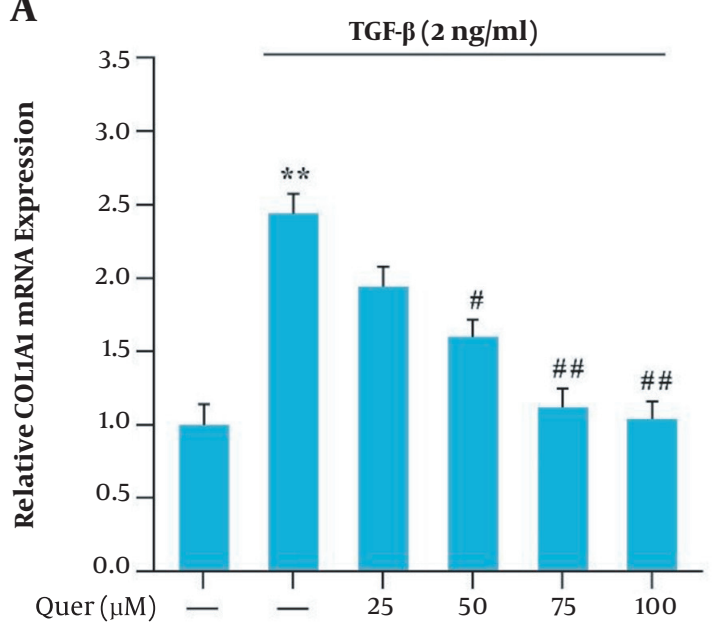

B

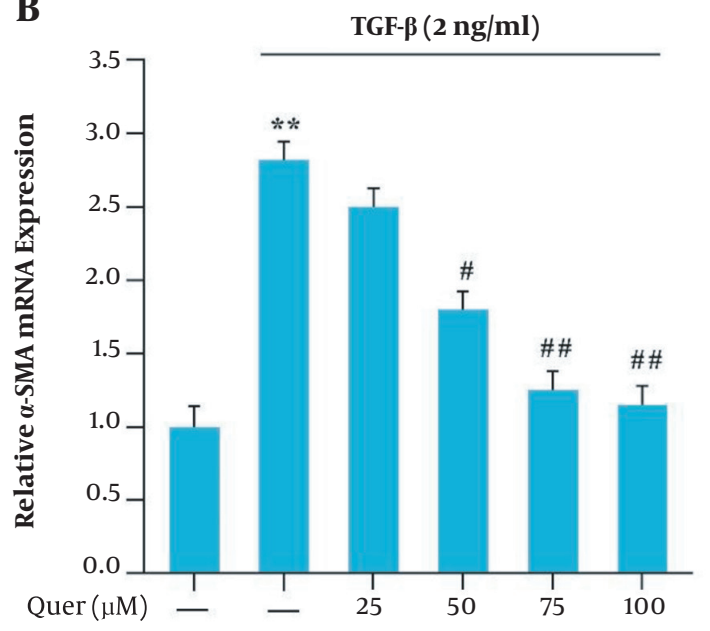

Figure 2. $\alpha$-SMA and Collagen1 $\alpha$ (COLA1) mRNA expression in the presence of TGF- $\beta$ ( $2 \mathrm{ng} / \mathrm{mL}$ ) and quercetin for $24 \mathrm{~h}$ in LX2 cell line: A, relative COLA1 mRNA expression in the presence of different concentrations of quercetin for $24 \mathrm{~h}$; B, relative $\alpha$-SMA mRNA expression in the presence of different concentrations of quercetin for $24 \mathrm{~h}$. Results are the mean \pm SEM of three replicates and expressed as fold changes in $\alpha$-SMA and COLA1 mRNA expression compared to the control group. GAPDH was used as the reference gene $\left({ }^{* *} \mathrm{P}<0.01\right.$ vs vehicle-treated control; $\# \mathrm{P}<0.05$ vs TGF- $\beta$ alone; $\# \# \mathrm{P}<0.01$ vs TGF- $\beta$ alone)

ited TGF- $\beta 1$-induced expression of $\alpha$-SMA and COL1 $\alpha 1$ in LX2 cell line. Hence, the inhibitory effect of quercetin in liver fibrosis may be closely related to decreasing TGF- $\beta$ production because the expression of TGF- $\beta$ in the HSCs was regulated by Smad2/3 phosphorylation. Quercetin has been shown to inhibit the $\mathrm{p}$-Smad3 and finally TGF- $\beta$ signaling pathway, which is consistent with other studies (22).

As a result, the data suggested that the possible mechanism of inhibition of liver fibrosis by the quercetin is due to the direct regulation of TGF- $\beta / \mathrm{p}-\mathrm{Smad} 3$ signaling path- way. Thus, suppression of TGF- $\beta$ expression may improve hepatic fibrosis, and its mechanism of action is through the TGF- $\beta /$ Smad3 signaling pathway. In summary, treatment with quercetin ultimately may inhibit the activation of HSCs in vitro.

\subsection{Conclusions}

We demonstrate that quercetin inhibits further activation of HSCs by inhibiting the TGF- $\beta /$ Smad3 signaling pathway and reduces ECM accumulation during liver fibrosis 
A TGF- $\beta$ (2 ng/ml)

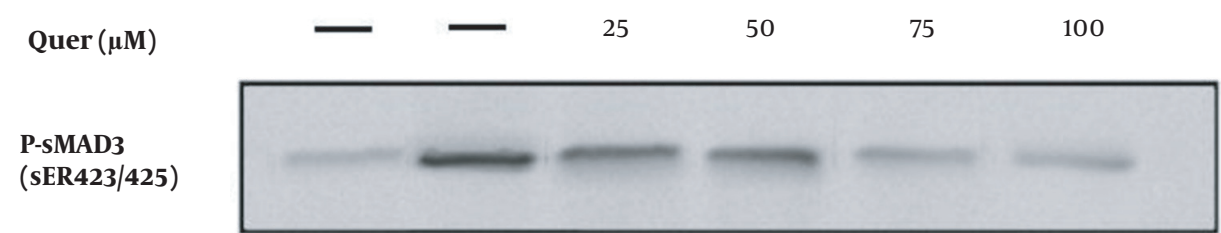

$52 \mathrm{KDa}$

GAPDH

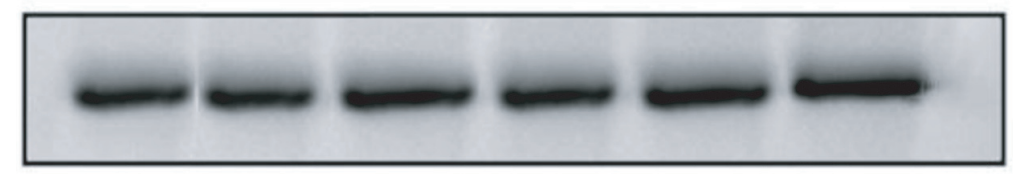

$37 \mathrm{KDa}$

B

TGF- $\beta$ (2 ng/ml)

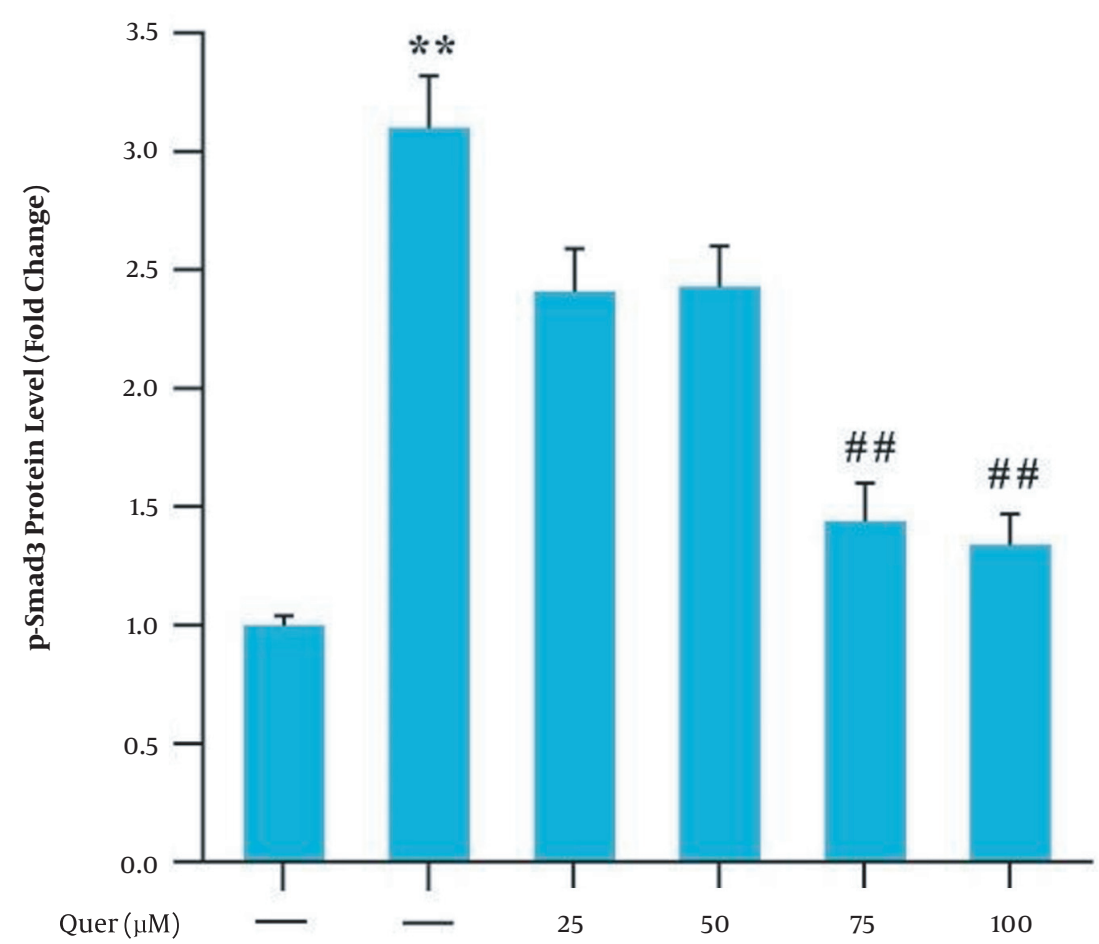

Figure 3. A, western blot analysis of Smad3C expressions in LX-2 cells. LX-2 cells were treated with different quercetin concentrations for 30 min before being incubated with concentrations of $2 \mathrm{ng} / \mathrm{mL}$ TGF- $\beta$ for $30 \mathrm{~min}$, the cell lysates were immunoblotted; B, the relative Smad3C level. The relative Smad3C level were expressed as the ratio Smad3C/GAPDH. The bands were analyzed with ImageJ software. The data were performed using one-way analysis of variance (ANOVA), followed by the Tukey's test. Data represent the mean \pm SEM of three replicates $\left({ }^{* *} \mathrm{P}<0.01\right.$ vs vehicle-treated control; \#\#P $<0.01$ vs TGF- $\beta$ alone). 
in vitro, and may prevent the progression of liver fibrosis. The use of quercetin is suggested as a potential therapeutic agent in the treatment of liver fibrosis.

\section{Acknowledgments}

This study was supported by the Ahvaz Jundishapur University of Medical Sciences (grant No. 99s65). The funding source has no role in the design of the study, analysis, and interpretation of data, and publication of the manuscript.

\section{Footnotes}

Authors' Contribution: NM designed the study. RA performed all assays. RA analysed the data. ESH wrote the first draft. MM revised the manuscript. The authors read and approved the final manuscript.

Conflict of Interests: All authors affirm that there are no conflicts of interest.

Ethical Approval: The present study was designed and conducted with the permission of the Ethics Committee of Ahwaz Jundishapur University of Medical Sciences (IR.AJUMS.REC.1399.650).

Funding/Support: This study was supported by the Ahvaz Jundishapur University of Medical Sciences.

Informed Consent: Informed written consent was obtained from all participants.

\section{References}

1. Sanchez-Valle V, Chavez-Tapia NC, Uribe M, Mendez-Sanchez N. Role of oxidative stress and molecular changes in liver fibrosis: A review. Curr Med Chem. 2012;19(28):4850-60. doi: 10.2174/092986712803341520. [PubMed: 22709007].

2. Hernandez-Gea V, Friedman SL. Pathogenesis of liver fibrosis. Annu Rev Pathol. 2011;6:425-56. doi: 10.1146/annurev-pathol-011110-130246. [PubMed: 21073339].

3. James OF, Day CP. Non-alcoholic steatohepatitis (NASH): A disease of emerging identity and importance. J Hepatol.1998;29(3):495-501. doi: 10.1016/s0168-8278(98)80073-1. [PubMed: 9765002].

4. Fabregat I, Caballero-Diaz D. Transforming growth factor-betainduced cell plasticity in liver fibrosis and hepatocarcinogenesis. Front Oncol. 2018;8:357. doi: 10.3389/fonc.2018.00357. [PubMed: 30250825]. [PubMed Central: PMC6139328].

5. Ghosh AK, Yuan W, Mori Y, Varga J. Smad-dependent stimulation of type I collagen gene expression in human skin fibroblasts by TGF-beta involves functional cooperation with p300/CBP transcriptional coactivators. Oncogene. 2000;19(31):3546-55. doi: 10.1038/sj.onc.1203693. [PubMed: 10918613].

6. Dooley S, Delvoux B, Streckert M, Bonzel L, Stopa M, ten Dijke P, et al. Transforming growth factor beta signal transduction in hepatic stellate cells via Smad2/3 phosphorylation, a pathway that is abrogated during in vitro progression to myofibroblasts. TGFbeta signal transduction during transdifferentiation of hepatic stellate cells. FEBS
Lett. 2001;502(1-2):4-10. doi: 10.1016/s0014-5793(01)02656-4. [PubMed: 11478938].

7. Liu X, Wang W, Hu H, Tang N, Zhang C, Liang W, et al. Smad3 specific inhibitor, naringenin, decreases the expression of extracellular matrix induced by TGF-beta1 in cultured rat hepatic stellate cells. Pharm Res. 2006;23(1):82-9. doi:10.1007/s11095-005-9043-5. [PubMed: 16341574].

8. Iredale JP, Thompson A, Henderson NC. Extracellular matrix degradation in liver fibrosis: Biochemistry and regulation. Biochim Biophys Acta. 2013;1832(7):876-83. doi: 10.1016/j.bbadis.2012.11.002. [PubMed: 23149387].

9. Trautwein C, Friedman SL, Schuppan D, Pinzani M. Hepatic fibrosis: Concept to treatment. J Hepatol. 2015;62(1 Suppl):S15-24. doi: 10.1016/j.jhep.2015.02.039. [PubMed: 25920084].

10. Lee YA, Wallace MC, Friedman SL. Pathobiology of liver fibrosis: A translational success story. Gut. 2015;64(5):830-41. doi: 10.1136/gutjnl2014-306842. [PubMed: 25681399]. [PubMed Central: PMC4477794].

11. Anand David AV, Arulmoli R, Parasuraman S. Overviews of biological importance of quercetin: A bioactive flavonoid. Pharmacogn Rev. 2016;10(20):84-9. doi: 10.4103/0973-7847.194044. [PubMed: 28082789]. [PubMed Central: PMC5214562].

12. Comalada M, Camuesco D, Sierra S, Ballester I, Xaus J, Galvez J, et al. In vivo quercitrin anti-inflammatory effect involves release of quercetin, which inhibits inflammation through down-regulation of the NF-kappaB pathway. Eur J Immunol. 2005;35(2):584-92. doi: 10.1002/eji.200425778. [PubMed: 15668926].

13. Wadsworth TL, Koop DR. Effects of the wine polyphenolics quercetin and resveratrol on pro-inflammatory cytokine expression in RAW 264.7 macrophages. Biochem Pharmacol. 1999;57(8):941-9. doi: 10.1016/s0006-2952(99)00002-7. [PubMed:10086329].

14. Wang L, Wang B, Li H, Lu H, Qiu F, Xiong L, et al. Quercetin, a flavonoid with anti-inflammatory activity, suppresses the development of abdominal aortic aneurysms in mice. Eur J Pharmacol. 2012;690(1-3):13341. doi: 10.1016/j.ejphar.2012.06.018. [PubMed: 22728078].

15. Bao Y, Pang Y, Tang S, Niu T, Guo Z, He H, et al.12N-Substituted matrinol derivatives inhibited the expression of fibrogenic genes via repressing integrin/FAK/PI3K/Akt pathway in hepatic stellate cells. Molecules. 2019;24(20). doi: 10.3390/molecules24203748. [PubMed: 31627430]. [PubMed Central: PMC6832694].

16. Mutlu Altundag E, Kasaci T, Yilmaz AM, Karademir B, Kocturk S, Taga Y, et al. Quercetin-induced cell death in human papillary thyroid cancer (B-CPAP) cells. J Thyroid Res. 2016;2016:9843675. doi: 10.1155/2016/9843675. [PubMed: 27057371]. [PubMed Central: PMC4745605].

17. Kisseleva T, Brenner DA. Role of hepatic stellate cells in fibrogenesis and the reversal of fibrosis. J Gastroenterol Hepatol. 2007;22 Suppl 1:S73-8. doi: 10.1111/j.1440-1746.2006.04658.x. [PubMed: 17567473].

18. Svegliati-Baroni G, De Minicis S, Marzioni M. Hepatic fibrogenesis in response to chronic liver injury: Novel insights on the role of cellto-cell interaction and transition. Liver Int. 2008;28(8):1052-64. doi: 10.1111/j.1478-3231.2008.01825.x. [PubMed: 18783548].

19. Zhou L, Dong X, Wang L, Shan L, Li T, Xu W, et al. Casticin attenuates liver fibrosis and hepatic stellate cell activation by blocking TGF-beta/Smad signaling pathway. Oncotarget. 2017;8(34):56267-80. doi:10.18632/oncotarget.17453. [PubMed: 28915589]. [PubMed Central: PMC5593560].

20. Kanzler S, Lohse AW, Keil A, Henninger J, Dienes HP, Schirmacher P, et al. TGF-beta1 in liver fibrosis: An inducible transgenic mouse model to study liver fibrogenesis. Am J Physiol. 1999;276(4):G1059-68. doi: 10.1152/ajpgi.1999.276.4.G1059. [PubMed: 10198351].

21. Hernandez-Ortega LD, Alcantar-Diaz BE, Ruiz-Corro LA, SandovalRodriguez A, Bueno-Topete M, Armendariz-Borunda J, et al. Quercetin improves hepatic fibrosis reducing hepatic stellate cells and regulating pro-fibrogenic/anti-fibrogenic molecules balance. J Gastroenterol Hepatol. 2012;27(12):1865-72. doi: 10.1111/j.1440-1746.2012.07262.x. [PubMed: 22989100]. 
22. Wu L, Zhang Q, Mo W, Feng J, Li S, Li J, et al. Quercetin prevents hepatic fibrosis by inhibiting hepatic stellate cell activation and reducing autophagy via the TGF-beta1/Smads and PI3K/Akt pathways. Sci Rep. 2017;7(1):9289. doi: 10.1038/s41598-017-09673-5. [PubMed: 28839277]. [PubMed Central: PMC5571156].

23. Li X, Jin Q, Yao Q, Xu B, Li L, Zhang S, et al. The flavonoid quercetin ameliorates liver inflammation and fibrosis by regulating hepatic macrophages activation and polarization in mice. Front Pharmacol. 2018;9:72. doi: 10.3389/fphar.2018.00072. [PubMed: 29497376]. [PubMed Central: PMC5819566].

24. Yang JH, Kim SC, Kim KM, Jang CH, Cho SS, Kim SJ, et al. Isorhamnetin attenuates liver fibrosis by inhibiting TGF-beta/Smad signaling and relieving oxidative stress. Eur J Pharmacol. 2016;783:92-102. doi: 10.1016/j.ejphar.2016.04.042. [PubMed: 27151496].

25. Ganbold M, Shimamoto Y, Ferdousi F, Tominaga K, Isoda H. Antifibrotic effect of methylated quercetin derivatives on TGFbetainduced hepatic stellate cells. Biochem Biophys Rep. 2019;20:100678. doi: 10.1016/j.bbrep.2019.100678. [PubMed: 31467991]. [PubMed Central: PMC6711851].

26. Li X, Liu HC, Yao QY, Xu BL, Zhang SC, Tu CT. Quercetin protects mice from ConA-induced hepatitis by inhibiting HMGB1-TLR expression and down-regulating the nuclear factor kappa B pathway. Inflammation. 2016;39(1):96-106. doi: 10.1007/s10753-015-0227-9. [PubMed: 26267064]. 